\title{
SARS-CoV-2 D614G variant exhibits efficient replication ex vivo and transmission in vivo
}

\author{
Yixuan J. Hou ${ }^{1 *}$, Shiho Chiba ${ }^{2 *}$, Peter Halfmann ${ }^{2}$, Camille Ehre $^{3}$, Makoto Kuroda $^{2}$, Kenneth H. Dinnon III \\ Sarah R. Leist ${ }^{1}$, Alexandra Schäfer ${ }^{1}$, Noriko Nakajima ${ }^{5}$, Kenta Takahashi ${ }^{5}$, Rhianna E. Lee ${ }^{3}$, Teresa M. Mascenik ${ }^{3}$, \\ Rachel Graham', Caitlin E. Edwards' ${ }^{1}$, Longping V. Tse ${ }^{1}$, Kenichi Okuda ${ }^{3}$, Alena J. Markmann ${ }^{6}$, Luther Bartelt ${ }^{6}$, \\ Aravinda de Silva ${ }^{4}$, David M. Margolis ${ }^{4,6}$, Richard C. Boucher ${ }^{3}$, Scott H. Randell ${ }^{3}$, Tadaki Suzuki ${ }^{5}$, \\ Lisa E. Gralinski', Yoshihiro Kawaoka ${ }^{2,7} \uparrow$, Ralph S. Baric ${ }^{1,4} \uparrow$ \\ ${ }^{1}$ Department of Epidemiology, University of North Carolina at Chapel Hill, Chapel Hill, NC, USA. Influenza Research Institute, Department of Pathobiological Sciences, School \\ of Veterinary Medicine, University of Wisconsin, Madison, WI, USA. ${ }^{3}$ Marsico Lung Institute, University of North Carolina at Chapel Hill, Chapel Hill, NC, USA. ${ }^{4}$ Department of \\ Microbiology and Immunology, University of North Carolina at Chapel Hill, Chapel Hill, NC, USA. ${ }^{5}$ Department of Pathology, National Institute of Infectious Diseases, Tokyo, \\ Japan. ${ }^{6}$ Department of Medicine, University of North Carolina at Chapel Hill, Chapel Hill, NC, USA. ${ }^{7}$ Division of Virology, Department of Microbiology and Immunology, Institute \\ of Medical Science, University of Tokyo, Tokyo, Japan. \\ *These authors contributed equally to this work. †Corresponding author. Email: yoshihiro.kawaoka@wisc.edu (Y.K.); rbaric@email.unc.edu (R.S.B.)
}

The spike D614G substitution is prevalent in global SARS-CoV-2 strains, but its effects on viral pathogenesis and transmissibility remain unclear. We engineered a SARS-CoV-2 variant containing this substitution. The variant exhibits more efficient infection, replication, and competitive fitness in primary human airway epithelial cells, but maintains similar morphology and in vitro neutralization properties, compared with the ancestral wild-type virus. Infection of human angiotensin-converting enzyme 2 (ACE2) transgenic mice and Syrian hamsters with both viruses resulted in similar viral titers in respiratory tissues and pulmonary disease. However, the D614G variant transmits significantly faster and displayed increased competitive fitness than the wild-type virus in hamsters. These data show that the D614G substitution enhances SARS-CoV-2 infectivity, competitive fitness, and transmission in primary human cells and animal models.

The expanding Coronavirus Disease 2019 (COVID-19) pandemic, caused by Severe Acute Respiratory Syndrome Coronavirus 2 (SARS-CoV-2), has had an unprecedented impact on modern human civilization, resulting in over 1.1 million deaths globally. Pandemic spread of the virus in naïve populations may select for mutations that alter pathogenesis, virulence and/or transmissibility. Despite the presence of a CoV proof-reading function in viral replication $(1,2)$, recent reports identified an emergent D614G substitution in the spike glycoprotein of SARS-CoV-2 strains that is now the most prevalent form globally. Patients infected with the D614G variant are associated with higher upper respiratory tract viral loads than seen with the ancestral strain, but not altered disease severity $(3,4)$. SARS-CoV-2 S pseudotyped viruses encoding the D614G substitution were reported to exhibit increased infectivity in continuous cell lines and increased sensitivity to neutralization $(4,5)$. Structural analyses also revealed that the receptor binding domains (RBD) in the G614-form S protein occupy a higher percentage in the open conformation than the D614-form, implying an improved ability to bind to the receptor angiotensin-converting enzyme 2 (ACE2) $(6,7)$. However, the D614G substitution has yet to be evaluated in the authentic SARS-CoV-2 infection models, and its functions in viral replication, pathogenesis and transmissibility remain unclear.
To address these questions, we generated an isogenic SARS-CoV-2 variant containing only the D614G substitution in the S glycoprotein, along with a second variant that contained the nanoLuciferease (nLuc) gene in place of accessory gene 7a (Fig. 1A), using a D614-form SARS-CoV-2 strain WA1 as the backbone (8). To examine whether the D614G substitution enhances authentic SARS-CoV-2 entry, four susceptible cell lines were infected with the ancestral wild-type (WT)nLuc and D614G-nLuc viruses and maintained in the medium containing neutralizing antibodies to limit viral spreading. Luciferase signals representing initial entry events were measured at $8 \mathrm{~h}$ post infection (Fig. 1B). In accord with pseudovirus studies $(4,9)$, the D614G-nLuc infection resulted in a 3.7 to 8.2-fold higher transgene expression as compared with WT-nLuc virus in different cell lines. Growth curves comparing WT and D614G viruses were performed in those cell lines (Fig. 1C). Although the D614G variant showed similar or slightly higher titers at the early time point (8h), its peak titers were $\sim 0.5 \operatorname{logs}$ lower than the ancestral WT virus in VeroE6 and A549-ACE2 cell lines but not in Vero-81 and Huh7.

To evaluate the replication of SARS-CoV-2 D614G variant in the human respiratory tract, we compared the multi-step growth kinetics $(\mathrm{MOI}=0.1)$ of the WT and D614G viruses in ex vivo primary human nasal epithelial (HNE) cells from five donors, large (proximal) airway epithelial (LAE) cells from 
four donors, and distal lung small airway epithelial (SAE) cells from three donors. Cultures from the same donor were infected with either WT or D614G virus in triplicate (Fig. 1, D to F, and fig. S1, A and B). Both viruses infect mainly ciliated cells in the primary pulmonary cultures (fig. S1C). Paired $t$ test analysis suggests the D614G-infected HNE at 24, 48 and 72 hours, and LAE cultures at 48 hours exhibited statistically higher titers than those infected with the WT virus. This enhanced replication was not observed at any timepoints in distal lung SAE cultures derived from three donors. To further compare replication fitness between the two variants, competition assays were performed in LAE cultures by infecting simultaneously with both viruses (Fig. 1G). After three continuous passages at $72 \mathrm{~h}$ intervals, the D614G variant became dominant in the cultures regardless of whether the WT virus was at a 1:1 or 10:1 ratio over the isogenic D614G mutant (Fig. $1, \mathrm{H}$ and I). Taken together, these data suggest the D614G substitution enhances SARS-CoV-2 replication fitness in the primary epithelial cells, with an advantage in the upper respiratory tract epithelial cells in nasal and large (proximal) airway epithelia that express higher levels of hACE2 receptor (8).

Next, scanning and transmission electron microscopy (SEM and TEM) were performed to visualize virions present on the surface of primary human airway cell cultures. No significant differences in virion morphology were detected (Fig. 2 , A and B). The number of spike proteins on individual virion projections was not significantly different between the two viruses in the EM images (Fig. 2C). Western blot analysis also shows similar spike to nucleocapsid ratios between the two viruses in samples collected from multiple HNE cultures (Fig. 2, D and E). Differences in spike cleavage were also not observed between the two viruses (Fig. 2, D and F). Further, we evaluated the neutralization properties of convalescent human serum samples $(n=25)$ using the nLuc-expressing recombinant SARS-CoV-2 encoding either WT or D614G spike (Fig. 2 , $\mathrm{G}$ and $\mathrm{H}$ ). The samples show similar half-maximal inhibitory dilution $\left(\mathrm{ID}_{50}\right)$ values against both viruses. Similarly, six RBD-binding, SARS-CoV-2 neutralizing monoclonal antibodies showed no significant difference at half-maximal inhibitory concentration $\left(\mathrm{IC}_{50}\right)$ values against both viruses (Fig. 2, I and $\mathrm{J}$ ). Together, these data suggest that the D614G substitution doesn't alter significantly SARS-CoV-2 morphology, spike cleavage pattern and in vitro neutralization properties in the context of live virus.

To evaluate the role of the D614G substitution in viral pathogenesis, $h A C E 2$ transgenic mice and Syrian hamsters were infected with equal plaque-forming units (PFU) of WT or D614G viruses. SARS-CoV-2 infection in hACE2 mice exhibited a mild disease phenotype, characterized by high viral titers in lung and brain tissues, but minimum weight loss and undetectable nasal titers (10). Two groups of $h A C E 2$ mice infected with WT or D614G viruses exhibited undetectable viral titers in nasal turbinates and similar lung viral titers at day 2 and 5 post infection. One mouse (1/5) from both groups exhibited detectible viral titers in the brain (Fig. 3A). Histopathological analyses reveal similar levels of lesions and SARS-CoV-2-infected cells in the mouse lung tissue harvested at day 2 post infection (Fig. 3B). With respect to hamster studies, lung and nasal turbinate tissues collected at day 3 and 6 pi exhibited similar viral titers in each group (Fig. 4, A and B). However, the D614G-infected hamsters lost slightly more body weight than those infected with the WT virus (Fig. 4C). Immunohistochemistry (IHC) shows similar levels of viral antigen staining in the hamster lung tissue collected at day 3 , 6 and 9 from both groups (Fig. 4, D and Fi). Histopathological examination revealed similar severe pulmonary lesions with inflammatory cell infiltration in the alveolar walls and air spaces, pulmonary edema, and alveolar hemorrhage in both of the hamsters on day 3 , extended across larger areas on day 6 , and then exhibiting partial resolution by day 9 (Fig. 4E). There was no significant difference in the size of the lung lesions (Fig. 4Fii) and the histological severity (Fig. 4Fiii). To evaluate the roles of the D614G variant replication fitness in vivo, we performed a competition assay in four independent lines of hamsters. Each hamster was infected with $1000 \mathrm{PFU}$ of a mixture containing a 1:1 ratio of both viruses (fig. S2B). After three continuous passages in naïve animals at 3-day intervals, we observed the D614G became dominant in the lung tissues of animals after the $1^{\text {st }}$ passage of all groups (fig. S2, C and D), consistent with the phenotype of enhanced fitness of the D614G virus noted in the human LAE competition assay. These studies indicate that the D614G substitution contributes to marginal enhancement of SARS-CoV-2 pathogenesis in hamsters, but not in $h A C E 2$ mice, and to improved competitive fitness in the hamster model.

To evaluate the impact of the D614G substitution in SARSCoV-2 respiratory transmissibility, we set up eight pairs of hamsters for each virus similar to previously studies $(11,12)$. Each pair comprised a naïve hamster adjacent to a cage with an infected animal 1 day after infection (fig. S2, E and F). Viral titers in the nasal wash samples from all animals were monitored. Both WT and D614G viruses were transmitted efficiently to naive hamsters evident by positive nasal wash samples detected in all exposed animals at day 4 (Fig. 4G). The infected groups at all three timepoints and the exposure groups at day 4 and 6 exhibited similar viral titers between the two viruses. However, five of eight hamsters exposed to the D614G-infected group showed infection and detectable viral shedding at day 2 while those exposed to the WTinfected group had no infection and viral shedding ( $p=$ 0.0256, Fisher exact test), supporting the hypothesis that the D614G variant transmits significantly faster than the WT virus between hamsters. 
Emerging viruses, like CoVs, Alphaviruses, and Filoviruses, have undergone sequential rounds of evolution while adapting to the new human hosts in epidemic or pandemic settings (13-15). Among CoVs, mutations in the spike glycoprotein have been associated with altered pathogenesis, receptor usage, and neutralization (16-19), potentially challenging the development of vaccine and therapeutic antibodies that are urgently needed at present. The emergent D614G mutation in the spike gene of SARS-CoV-2 strains has raised significant concerns about potential enhancements in transmissibility, antigenicity, and/or pathogenesis. Using authentic SARS-CoV-2 isogenic variants, we show the role of the D614G substitution in enhancing viral infectivity in immortalized cell lines, growth, and fitness in primary human airway epithelial cells and hamsters, yet, it marginally alters viral pathogenesis in hamster and hACE2 mouse models. Importantly, we demonstrate that the D614G variant transmits significantly faster between hamsters through aerosol and droplets.

Recent studies indicate that D614G alters spike trimer hydrogen-bond interactions, reorienting the RBD into an "up" conformation, increasing ACE2 receptor binding and infectivity $(7,20)$. Consistent with previous pseudotype virus studies $(4,9,21,22)$, our data show that the D614G recombinant virus enters immortalized cell lines more efficiently than the WT virus. However, we didn't observe the enhancement of viral titers in continuous replication kinetics, suggesting the variable ACE2 and protease levels between different cell lines and the virion thermostability may also affect to the D614G replication in vitro. Importantly, the efficient replication and fitness in our ex vivo models suggest that SARS-CoV-2 D614G isogenic virus displays a significant advantage in epithelial cells in the nose and upper respiratory tract. These data support the role of the nasal epithelium and the D614G substitution in enhanced infectivity and transmission in human populations (3).

Patients infected with the D614G virus have not been conclusively linked to increased disease severity $(3,4)$. In this study, we evaluated the pathogenesis of the D614G variants in both $h A C E 2$ mouse and hamster models. Equivalent virus titers were measured in the lungs and nasal turbinates of all time points, and similar severity of lesions were observed in the histopathological samples, suggesting the D614G substitution doesn't significantly enhance the SARS-CoV-2 pathogenesis in both animal models, although this phenotype needs to be confirmed in both sexes of animals in future studies. However, the increased weight loss and improved in vivo replication fitness in hamsters suggest the D614G variant may cause marginally enhanced disease outcomes. Although complicated by the presence of other mutations in the spike, these differences may become more evident in a lethal SARS$\mathrm{CoV}-2$ infection model in young, adult or aged mice in future studies (23). In the hamster transmission study, the D614G isogenic transmitted significantly faster to adjacent animals early in infection, showing that the substitution preserved efficient transmission in vivo. As SARS-CoV-2 replicates preferentially in the nasal and olfactory epithelium, depending on differences in ACE2 and TMPRSS2 cell type expression patterns across species $(8,24,25)$, these data are consistent with a model of increased replication in the nasal epithelium and large airway epithelium, leading to enhanced virus growth compared with the ancestral virus and more efficient transmissibility. Potential reasons for this phenotype could be that the D614G variant exhibits lower minimum infectious dose to animals and/or to subtle variations in virion stability in small/large droplets, which requires further mechanistic studies in the future.

Using pseudotype viruses, the D614G substitution has been suggested to increase proteolytic cleavage and S glycoprotein incorporation into virions, reduce S1 loss and promote enhanced infectivity in vitro $(4,9,21)$. In the backdrop of a full complement of SARS-CoV-2 structural proteins, our study demonstrated no obvious differences in proteolytic processing or $\mathrm{S}$ incorporation into isogenic virions encoding the D614G mutations, perhaps reflecting differences in $\mathrm{S}$ trimer incorporation and presentation between authentic and pseuotyped viruses; the latter lack a full component of virion proteins. The effect of the $\mathrm{D} 614 \mathrm{G}$ variant on vaccine efficacy has been of major concern. Consistent with previous studies (5, 22 ), we showed overall equivalent sensitivity of the both luciferase reporter viruses to the 25 convalescent human sera and 6 RBD-binding mAbs, suggesting the D614G substitution does not significantly shift SARS-CoV-2 neutralization properties. Some sera and mAbs, such as serum \#1 and REGN10987, displayed slightly different neutralization potencies against the two viruses, suggesting subtle differences in the $\mathrm{Ab}$ binding properties. As a limitation, the virus genotype in most serum donors remains unknown. These data also suggest that the current vaccine approaches directed against WT spike should be effective against the D614G strains. The relationship between increased transmission and virulence remains complex and could be impacted by age, sex and other comorbidities, and it is unclear whether the minimum infectious dose may be lower for D614G in humans (26). It is clearly important to monitor and identify the emergence of new variants of SARS-CoV-2 with increased transmission and pathogenesis and/or altered antigenicity, especially as levels of human herd immunity and active interventions alter the selective forces that operate on the genome.

\section{REFERENCES AND NOTES}

1. M. R. Denison, R. L. Graham, E. F. Donaldson, L. D. Eckerle, R. S. Baric, Coronaviruses: An RNA proofreading machine regulates replication fidelity and diversity. RNA Biol. 8, 270-279 (2011). doi:10.4161/rna.8.2.15013 Medline

2. R. L. Graham, M. M. Becker, L. D. Eckerle, M. Bolles, M. R. Denison, R. S. Baric, A live, impaired-fidelity coronavirus vaccine protects in an aged, immunocompromised 
mouse model of lethal disease. Nat. Med. 18, 1820-1826 (2012). doi:10.1038/nm.2972 Medline

3. R. Lorenzo-Redondo, H. H. Nam, S. C. Roberts, L. M. Simons, L. J. Jennings, C. Qi, C. J. Achenbach, A. R. Hauser, M. G. Ison, J. F. Hultquist, E. A. Ozer, A unique clade of SARS-CoV-2 viruses is associated with lower viral loads in patient upper airways. medRxiv 2020.05.19.20107144 [Preprint]. 21 June 2020; https://doi.org/10.1101/2020.05.19.20107144.

4. B. Korber, W. M. Fischer, S. Gnanakaran, H. Yoon, J. Theiler, W. Abfalterer, N. Hengartner, E. E. Giorgi, T. Bhattacharya, B. Foley, K. M. Hastie, M. D. Parker, D. G. Partridge, C. M. Evans, T. M. Freeman, T. I. de Silva, C. McDanal, L. G. Perez, H. Tang, A. Moon-Walker, S. P. Whelan, C. C. LaBranche, E. O. Saphire, D. C. Montefiori, A. Angyal, R. L. Brown, L. Carrilero, L. R. Green, D. C. Groves, K. J. Johnson, A. J. Keeley, B. B. Lindsey, P. J. Parsons, M. Raza, S. Rowland-Jones, N. Smith, R. M. Tucker, D. Wang, M. D. Wyles, Sheffield COVID-19 Genomics Group, Tracking changes in SARS-CoV-2 spike: Evidence that D614G increases infectivity of the COVID-19 virus. Cell 182, 812-827.e19 (2020). doi:10.1016/j.cell.2020.06.043 Medline

5. D. Weissman, M.-G. Alameh, C. C. LaBranche, R. J. Edwards, L. Sutherland, S. Santra, K. Mansouri, S. Gobeil, C. McDanal, N. Pardi, P. A. Shaw, M. G. Lewis, C. Boesler, U. Sahin, P. Acharya, B. F. Haynes, B. Korber, D. C. Montefiori, D614G spike mutation increases SARS CoV-2 susceptibility to neutralization. medRxiv 2020.07.22.20159905 [Preprint]. 12 September 2020; https://doi.org/10.1101/2020.07.22.20159905.

6. L. Yurkovetskiy, X. Wang, K. E. Pascal, C. Tomkins-Tinch, T. P. Nyalile, Y. Wang, A. Baum, W. E. Diehl, A. Dauphin, C. Carbone, K. Veinotte, S. B. Egri, S. F. Schaffner, J. E. Lemieux, J. B. Munro, A. Rafique, A. Barve, P. C. Sabeti, C. A. Kyratsous, N. V. Dudkina, K. Shen, J. Luban, Structural and functional analysis of the D614G SARSCoV-2 spike protein variant. Cell 183, 739-751.e8 (2020). 10.1016/i.cell.2020.09.032 Medline

7. R. A. Mansbach, S. Chakraborty, K. Nguyen, D. Montefiori, B. Korber, S. Gnanakaran, The SARS-CoV-2 spike variant D614G favors an open conformational state. bioRxiv 2020.07.26.219741 [Preprint]. 26 July 2020; https://doi.org/10.1101/2020.07.26.219741.

8. Y. J. Hou, K. Okuda, C. E. Edwards, D. R. Martinez, T. Asakura, K. H. Dinnon III, T. Kato, R. E. Lee, B. L. Yount, T. M. Mascenik, G. Chen, K. N. Olivier, A. Ghio, L. V. Tse, S. R. Leist, L. E. Gralinski, A. Schäfer, H. Dang, R. Gilmore, S. Nakano, L. Sun, M. L. Fulcher, A. Livraghi-Butrico, N. I. Nicely, M. Cameron, C. Cameron, D. J. Kelvin, A. de Silva, D. M. Margolis, A. Markmann, L. Bartelt, R. Zumwalt, F. J. Martinez, S. P. Salvatore, A. Borczuk, P. R. Tata, V. Sontake, A. Kimple, I. Jaspers, W. K. O'Neal, S. H. Randell, R. C. Boucher, R. S. Baric, SARS-CoV-2 reverse genetics reveals a variable infection gradient in the respiratory tract. Cell 182, 429-446.e14 (2020). doi:10.1016/i.cell.2020.05.042 Medline

9. Q. Li, J. Wu, J. Nie, L. Zhang, H. Hao, S. Liu, C. Zhao, Q. Zhang, H. Liu, L. Nie, H. Qin, M. Wang, Q. Lu, X. Li, Q. Sun, J. Liu, L. Zhang, X. Li, W. Huang, Y. Wang, The impact of mutations in SARS-CoV-2 spike on viral infectivity and antigenicity. Cell 182, 1284-1294.e9 (2020). doi:10.1016/i.cell.2020.07.012 Medline

10. K. H. Dinnon III, S. R. Leist, A. Schäfer, C. E. Edwards, D. R. Martinez, S. A. Montgomery, A. West, B. L. Yount Jr., Y. J. Hou, L. E. Adams, K. L. Gully, A. J. Brown, E. Huang, M. D. Bryant, I. C. Choong, J. S. Glenn, L. E. Gralinski, T. P. Sheahan, R. S. Baric, A mouse-adapted model of SARS-CoV-2 to test COVID-19 countermeasures. Nature 586, 560-566 (2020). doi:10.1038/s41586-0202708-8 Medline

11. M. Imai, T. Watanabe, M. Hatta, S. C. Das, M. Ozawa, K. Shinya, G. Zhong, A. Hanson, H. Katsura, S. Watanabe, C. Li, E. Kawakami, S. Yamada, M. Kiso, Y. Suzuki, E. A. Maher, G. Neumann, Y. Kawaoka, Experimental adaptation of an influenza $\mathrm{H} 5 \mathrm{HA}$ confers respiratory droplet transmission to a reassortant $\mathrm{H} 5$ HA/H1N1 virus in ferrets. Nature 486, 420-428 (2012). doi:10.1038/nature10831 Medline

12. M. Imai, K. Iwatsuki-Horimoto, M. Hatta, S. Loeber, P. J. Halfmann, N. Nakajima, T. Watanabe, M. Ujie, K. Takahashi, M. Ito, S. Yamada, S. Fan, S. Chiba, M. Kuroda, L. Guan, K. Takada, T. Armbrust, A. Balogh, Y. Furusawa, M. Okuda, H. Ueki, A. Yasuhara, Y. Sakai-Tagawa, T. J. S. Lopes, M. Kiso, S. Yamayoshi, N. Kinoshita, N. Ohmagari, S. I. Hattori, M. Takeda, H. Mitsuya, F. Krammer, T. Suzuki, Y. Kawaoka, Syrian hamsters as a small animal model for SARS-CoV-2 infection and countermeasure development. Proc. Natl. Acad. Sci. U.S.A. 117, 16587-16595
(2020). Medline

13. R. A. Urbanowicz, C. P. McClure, A. Sakuntabhai, A. A. Sall, G. Kobinger, M. A. Müller, E. C. Holmes, F. A. Rey, E. Simon-Loriere, J. K. Ball, Human adaptation of Ebola virus during the West African outbreak. Cell 167, 1079-1087.e5 (2016). doi:10.1016/i.cell.2016.10.013 Medline

14. K. A. Tsetsarkin, S. C. Weaver, Sequential adaptive mutations enhance efficient vector switching by Chikungunya virus and its epidemic emergence. PLOS Pathog. 7, e1002412 (2011). doi:10.1371/journal.ppat.1002412 Medline

15. The Chinese SARS Molecular Epidemiology Consortium, Molecular evolution of the SARS coronavirus during the course of the SARS epidemic in China. Science 303 , 1666-1669 (2004). doi:10.1126/science.1092002 Medline

16. J. ter Meulen, E. N. van den Brink, L. L. M. Poon, W. E. Marissen, C. S. W. Leung, F. Cox, C. Y. Cheung, A. Q. Bakker, J. A. Bogaards, E. van Deventer, W. Preiser, H. W. Doerr, V. T. Chow, J. de Kruif, J. S. M. Peiris, J. Goudsmit, Human monoclonal antibody combination against SARS coronavirus: Synergy and coverage of escape mutants. PLOS Med. 3, e237 (2006). doi:10.1371/journal.pmed.0030237 Medline

17. B. Rockx, T. Sheahan, E. Donaldson, J. Harkema, A. Sims, M. Heise, R. Pickles, M. Cameron, D. Kelvin, R. Baric, Synthetic reconstruction of zoonotic and early human severe acute respiratory syndrome coronavirus isolates that produce fatal disease in aged mice. J. Virol. 81, 7410-7423 (2007). doi:10.1128/JVl.00505-07 Medline

18. M. Letko, K. Miazgowicz, R. McMinn, S. N. Seifert, I. Sola, L. Enjuanes, A. Carmody, N. van Doremalen, V. Munster, Adaptive evolution of MERS-CoV to species variation in DPP4. Cell Rep. 24, 1730-1737 (2018). doi:10.1016/i.celrep.2018.07.045 Medline

19. C. E. Edwards, B. L. Yount, R. L. Graham, S. R. Leist, Y. J. Hou, K. H. Dinnon III, A. C. Sims, J. Swanstrom, K. Gully, T. D. Scobey, M. R. Cooley, C. G. Currie, S. H. Randell, R. S. Baric, Swine acute diarrhea syndrome coronavirus replication in primary human cells reveals potential susceptibility to infection. Proc. Natl. Acad. Sci. U.S.A. 117, 26915-26925 (2020). doi:10.1073/pnas.2001046117 Medline

20. I. O. Omotuyi, O. Nash, O. B. Ajiboye, C. G. Iwegbulam, E. B. Oyinloye, O. A. Oyedeji, Z. A. Kashim, K. Okaiyeto, Atomistic simulation reveals structural mechanisms underlying D614G spike glycoprotein-enhanced fitness in SARS-COV-2. J. Comput. Chem. 41, 2158-2161 (2020). doi:10.1002/jcc.26383 Medline

21. L. Zhang, C. B. Jackson, H. Mou, A. Ojha, E. S. Rangarajan, T. Izard, M. Farzan, H. Choe, The D614G mutation in the SARS-CoV-2 spike protein reduces S1 shedding and increases infectivity. bioRxiv 2020.06.12.148726 [Preprint]. 12 June 2020; https://doi.org/10.1101/2020.06.12.148726.

22. G. Beaudoin-Bussières, A. Laumaea, S. P. Anand, J. Prévost, R. Gasser, G. Goyette, H. Medjahed, J. Perreault, T. Tremblay, A. Lewin, L. Gokool, C. Morrisseau, P. Bégin, C. Tremblay, V. Martel-Laferrière, D. E. Kaufmann, J. Richard, R. Bazin, A. Finzi, Decline of humoral responses against SARS-CoV-2 spike in convalescent individuals. mBio 11, e02590-20 (2020). doi:10.1128/mBio.02590-20 Medline

23. S. R. Leist, K. H. Dinnon III, A. Schäfer, L. V. Tse, K. Okuda, Y. J. Hou, A. West, C. E. Edwards, W. Sanders, E. J. Fritch, K. L. Gully, T. Scobey, A. J. Brown, T. P. Sheahan, N. J. Moorman, R. C. Boucher, L. E. Gralinski, S. A. Montgomery, R. S. Baric, A mouse-adapted SARS-CoV-2 induces acute lung injury and mortality in standard laboratory mice. Cell 10.1016/j.cell.2020.09.050 (2020). doi:10.1016/i.cell.2020.09.050 Medline

24. B. Rockx, T. Kuiken, S. Herfst, T. Bestebroer, M. M. Lamers, B. B. Oude Munnink, D. de Meulder, G. van Amerongen, J. van den Brand, N. M. A. Okba, D. Schipper, P. van Run, L. Leijten, R. Sikkema, E. Verschoor, B. Verstrepen, W. Bogers, J. Langermans, C. Drosten, M. Fentener van Vlissingen, R. Fouchier, R. de Swart, M. Koopmans, B. L. Haagmans, Comparative pathogenesis of COVID-19, MERS, and SARS in a nonhuman primate model. Science 368, 1012-1015 (2020). doi:10.1126/science. abb7314 Medline

25. W. Sungnak, N. Huang, C. Bécavin, M. Berg, R. Queen, M. Litvinukova, C. TalaveraLópez, H. Maatz, D. Reichart, F. Sampaziotis, K. B. Worlock, M. Yoshida, J. L. Barnes, HCA Lung Biological Network, SARS-CoV-2 entry factors are highly expressed in nasal epithelial cells together with innate immune genes. Nat. Med. 26, 681-687 (2020). doi:10.1038/s41591-020-0868-6 Medline

26. S. Alizon, A. Hurford, N. Mideo, M. Van Baalen, Virulence evolution and the tradeoff hypothesis: History, current state of affairs and the future. J. Evol. Biol. 22, 245-259 (2009). doi:10.1111/i.1420-9101.2008.01658.x Medline

27. Y. Wu, F. Wang, C. Shen, W. Peng, D. Li, C. Zhao, Z. Li, S. Li, Y. Bi, Y. Yang, Y. Gong, 
H. Xiao, Z. Fan, S. Tan, G. Wu, W. Tan, X. Lu, C. Fan, Q. Wang, Y. Liu, C. Zhang, J. Qi, G. F. Gao, F. Gao, L. Liu, A noncompeting pair of human neutralizing antibodies block COVID-19 virus binding to its receptor ACE2. Science 368, 1274-1278 (2020). doi:10.1126/science.abc2241 Medline

28. J. Hansen, A. Baum, K. E. Pascal, V. Russo, S. Giordano, E. Wloga, B. O. Fulton, Y. Yan, K. Koon, K. Patel, K. M. Chung, A. Hermann, E. Ullman, J. Cruz, A. Rafique, T. Huang, J. Fairhurst, C. Libertiny, M. Malbec, W. Y. Lee, R. Welsh, G. Farr, S. Pennington, D. Deshpande, J. Cheng, A. Watty, P. Bouffard, R. Babb, N. Levenkova, C. Chen, B. Zhang, A. Romero Hernandez, K. Saotome, Y. Zhou, M. Franklin, S. Sivapalasingam, D. C. Lye, S. Weston, J. Logue, R. Haupt, M. Frieman, G. Chen, W. Olson, A. J. Murphy, N. Stahl, G. D. Yancopoulos, C. A. Kyratsous, Studies in humanized mice and convalescent humans yield a SARS-CoV-2 antibody cocktail. Science 369, 1010-1014 (2020). Medline

29. D. Pinto, Y.-J. Park, M. Beltramello, A. C. Walls, M. A. Tortorici, S. Bianchi, S. Jaconi, K. Culap, F. Zatta, A. De Marco, A. Peter, B. Guarino, R. Spreafico, E. Cameroni, J. B. Case, R. E. Chen, C. Havenar-Daughton, G. Snell, A. Telenti, H. W. Virgin, A. Lanzavecchia, M. S. Diamond, K. Fink, D. Veesler, D. Corti, Cross-neutralization of SARS-CoV-2 by a human monoclonal SARS-CoV antibody. Nature 583, 290-295 (2020). doi:10.1038/s41586-020-2349-y Medline

30. M. L. Fulcher, S. H. Randell, in Epithelial Cell Culture Protocols, S. H. Randell, M. L. Fulcher, Eds. (Methods in Molecular Biology Series, Humana Press, ed. 2, 2013), pp. 109-121.

\section{ACKNOWLEDGMENTS}

We thank Dr. Takafumi Kato at UNC Marsico Lung Institute for technical support on primary cells. We thank Ms. Yuko Sato at Japan National Institute of Infectious Diseases for technical support with pathological analysis. We thank Mr. David Hinkel at University of Wisconsin for setting up hamster transmission experiments. We are grateful to Adimab LLC. for providing us SARS-CoV-2 mAbs. We are grateful for the support of Susan Weiss, Y. Park, and Joann Kuruc, and the UNC Blood Donor Center for COVID-19 serum sample acquisition. The authors would like to thank all of the individuals who donated their plasma to the UNC Blood Donation Center. Information relating to IRB, IBC, and IACUC documents are available in the supplementary materials. Funding: This work was supported by grants from the U.S. National Institutes of Health, including R01-Al110700, U54-CA260543, U01-Al151797, UM1-Al126619 and R01-Al069274 along with contracts HHSN272201700036I and HHSN272201400008C. This work was supported in part by the Japan Agency for Medical Research and Development under grant numbers JP19fk0108113, JP19fm0108006, JP20fk0108104 and JP19fk0108110. This project was also supported by the North Carolina Policy Collaboratory at the University of North Carolina at Chapel Hill with funding from the North Carolina Coronavirus Relief Fund established and appropriated by the North Carolina General Assembly. Author contributions: YJH, YK and RSB conceived the study; YJH, SC, PH, CE and LEG performed most of the experiments; MK, KHD iii, SRL and AS assisted animal experiments; REL, TMK, RG, CEE assisted in vitro experiments; NN, KT and TS performed histological analyses; LVT, KO, AJM, LB, ADS, DMM, RCB and SHR provided essential materials and reagents; $Y K, R S B, P H$ and LEG supervised the research; YJH wrote the manuscript and generated the illustrations; YK, RSB reviewed and edited the manuscript. All authors read and approved the final manuscript. Competing interests: The authors declare no competing financial interests. Data and materials availability: All data are available in the manuscript or the supplementary materials. The recombinant viruses icSARSCoV-2-D614G and cSARS-CoV-2-D614G-nLuc used in this work are available from the corresponding authors under a material agreement with The University of North Carolina at Chapel Hill. This work is licensed under a Creative Commons Attribution 4.0 International (CC BY 4.0) license, which permits unrestricted use, distribution, and reproduction in any medium, provided the original work is properly cited. To view a copy of this license, visit https://creativecommons.org/licenses/by/4.0/. This license does not apply to figures/photos/artwork or other content included in the article that is credited to a third party; obtain authorization from the rights holder before using such material.

\section{SUPPLEMENTARY MATERIALS}

science.sciencemag.org/cgi/content/full/science.abe8499/DC1

Materials and Methods

Figs. S1 and S2

References (27-30)

MDAR Reproducibility Checklist

17 September 2020; accepted 9 November 2020

Published online 12 November 2020

10.1126/science.abe8499 

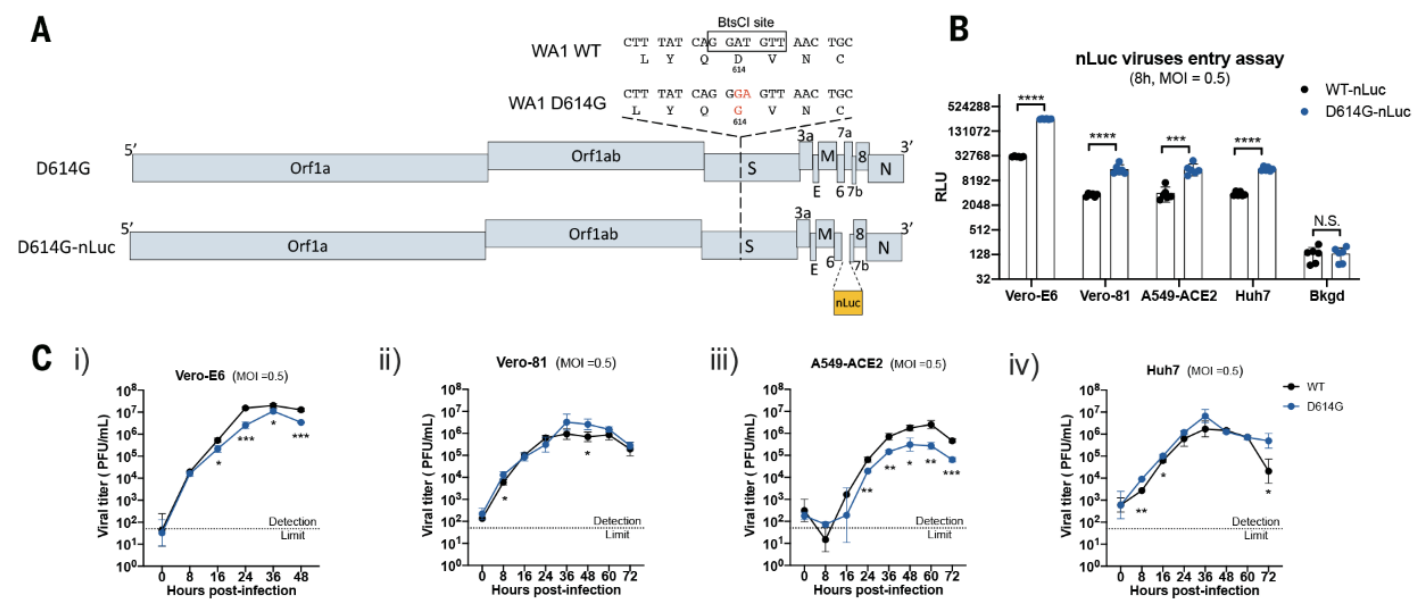

D
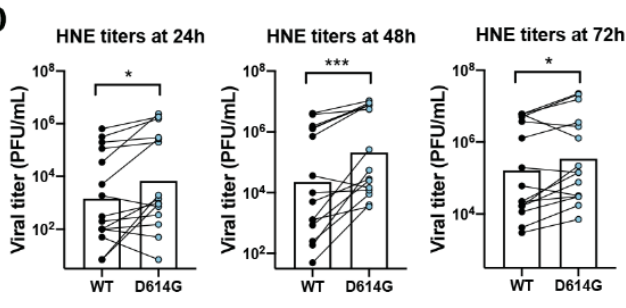

$\mathbf{E}$
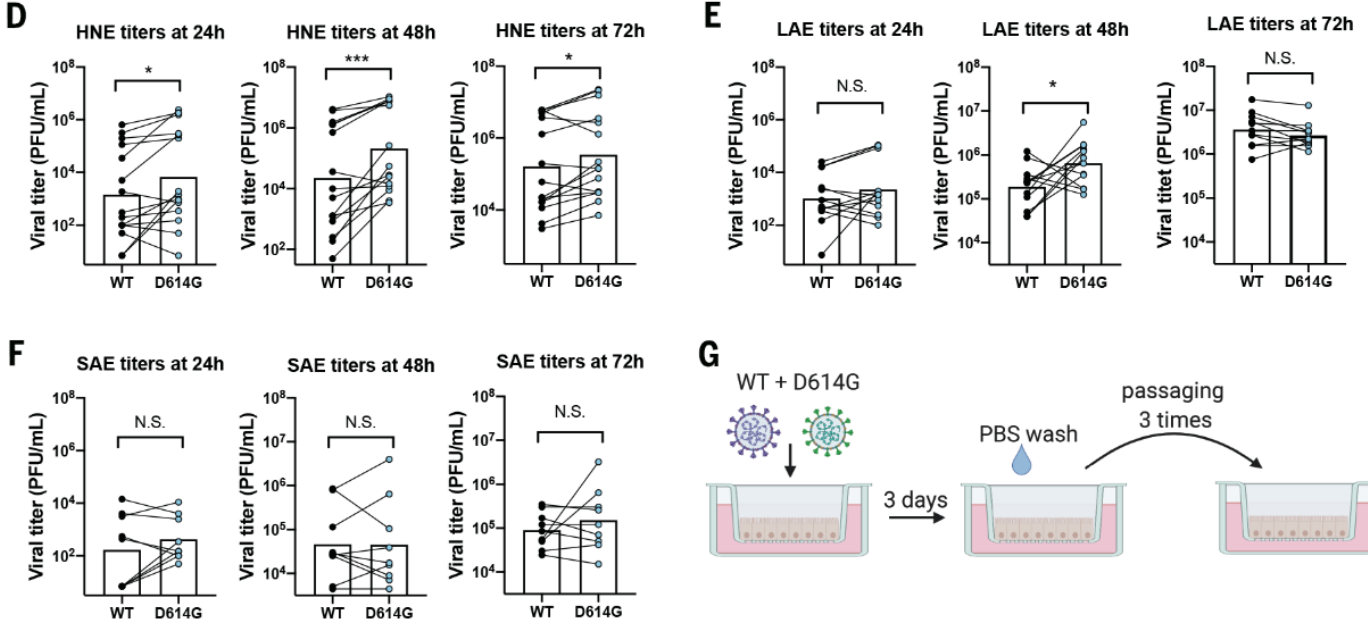

G
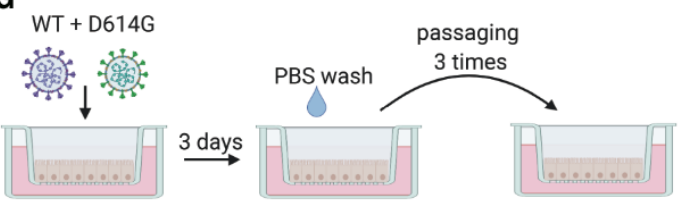

H
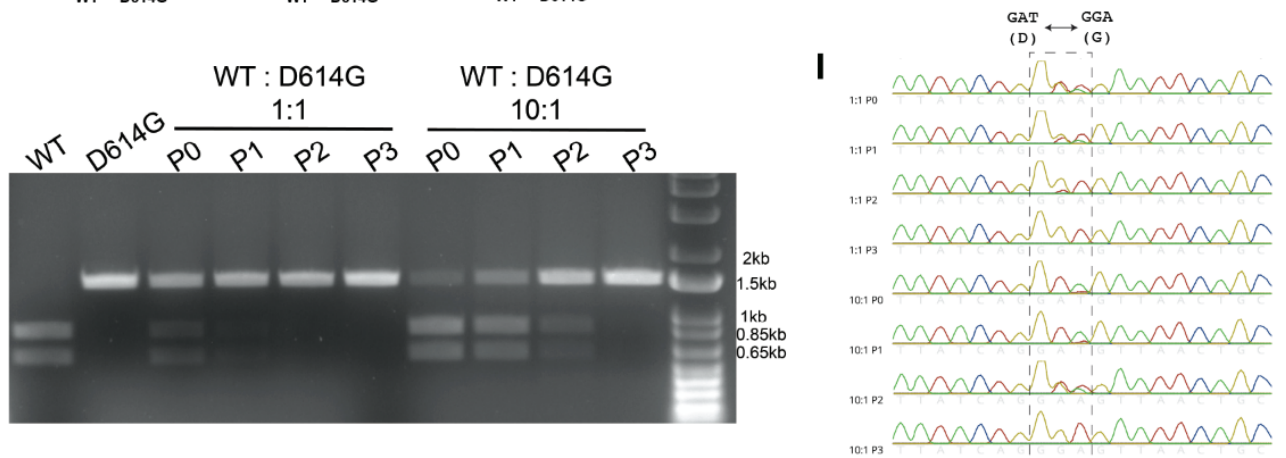
Fig. 1. SARS-CoV-2 D614G variant shows enhanced infectivity in immortalized cell lines and replication fitness in upper human respiratory epithelia compared with the ancestral WT virus. (A) Genomes of recombinant SARS-CoV-2 D614G variants based on the backbone of a D614-form strain WA1. (B) Entry efficiency of WT-nLuc and D614G-nLuc in multiple susceptible cell lines at MOI of 0.5 . After $1 \mathrm{~h}$ infection, cells were treated with neutralization antibodies to minimize the secondary round of infection. The relative light unit $(R L U)$ representing the nLuc expression level was measured at $8 \mathrm{~h}$ post infection. RLU values were normalized with background (Bkgd) residual luciferase signals in both viral inocula. (C) Growth curves of the two viruses in Vero-E6 (i), Vero-81 (ii), A549-ACE2 (iii) and Huh7 (iv) cell lines at $\mathrm{MOI}=0.5$. ( $\mathrm{D}$ to F) Comparison of 24,48 and $72 \mathrm{~h}$ titers between the two variants infected primary nasal (D), large airway (E) and small airway (F) cells at $\mathrm{MOI}$ of 0.1 . Triplicated titers of the two viruses in the cultures from the same donor were analyzed by paired $t$ test. (G) Schematic of competition assays on large airway epithelial cells. Cultures were infected with 1:1 or 10:1 ratio of WT and D614G mixture at $\mathrm{MOI}$ of 0.5 , and the supernatants were serially passaged three times in naïve cultures. ( $\mathrm{H}$ and $\mathrm{I}$ ) $\mathrm{Bts} \mathrm{Cl}$ digestion $(\mathrm{H})$ and Sanger sequencing chromatogram (I) of $\mathrm{S}$ gene fragments amplified from viral samples in the LAE competition assay. The $1.5 \mathrm{~kb}$ fragments containing the residue 614 were amplified from the total RNA of individual samples collected in each passage. Data in (B) and (C) are indicated as mean \pm SD and analyzed by unpaired $t$ test between both viruses; data in (D) to (F) are analyzed by paired $t$ test. N.S., not significantly different; ${ }^{*}, p<$ $0.05 ;{ }^{* *}, p<0.01 ;{ }^{* * *}, p<0.001 ;{ }^{* * *}, p<0.0001$. 
A

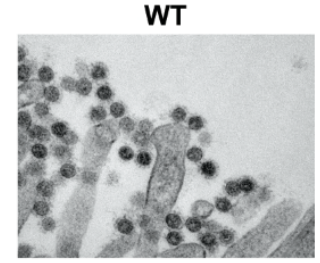

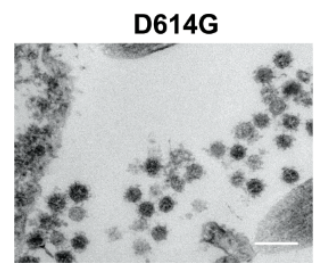

B
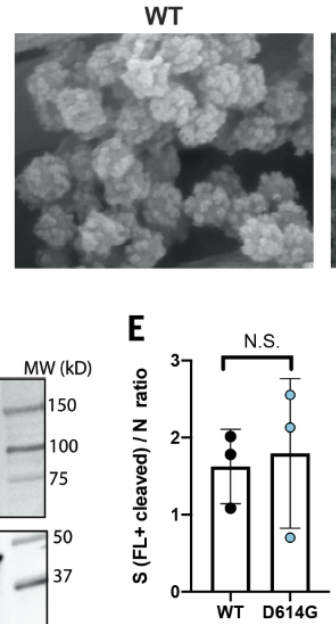

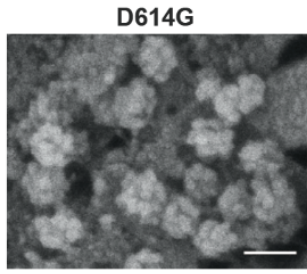

$\mathbf{F}$

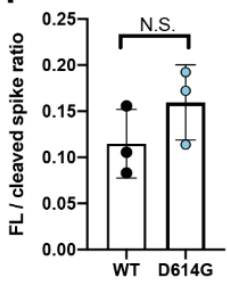

G

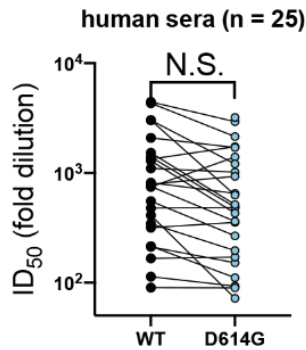

I

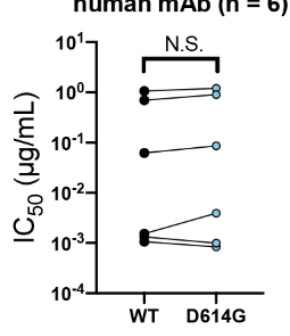

H
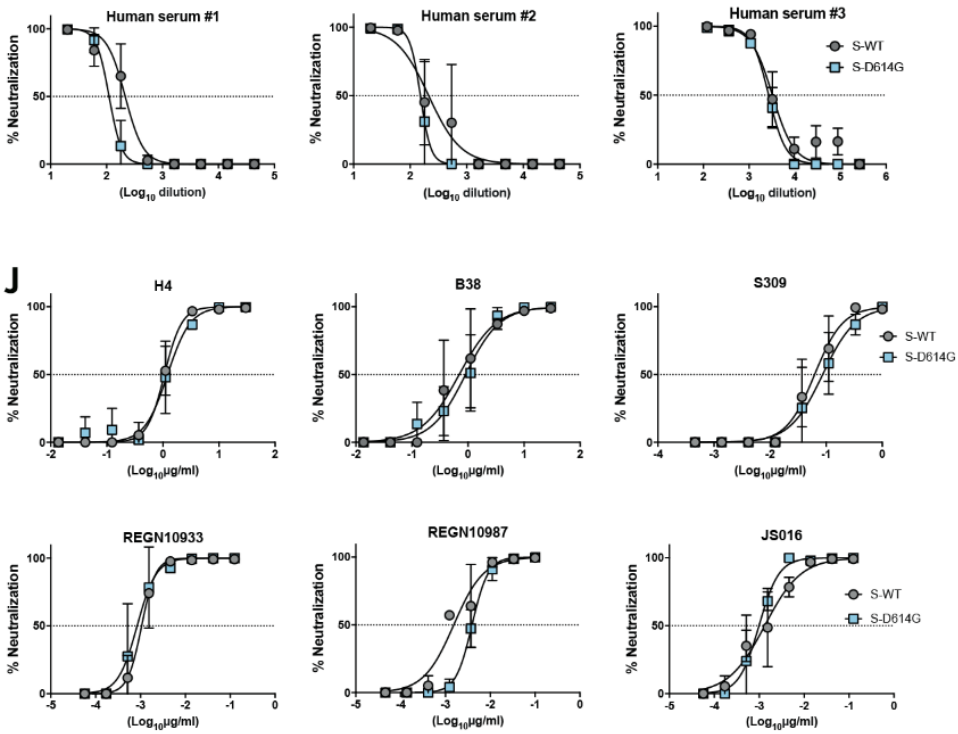

Fig. 2. D614G substitution does not alter SARS-CoV-2 virion morphology, S protein cleavage patterns and sensitivity to neutralizing antibodies. (A) Transmission electron microscopy image of WT and D614G virions on airway epithelial cell surface, scale bar: $200 \mathrm{~nm}$. (B) Scanning electron microscopy images of WT and D614G virions on airway epithelial cell surface, scale bar: $100 \mathrm{~nm}$. (C) Quantification of S protein on individual SARS-CoV-2 virion projections. The number of S proteins on individual virion projections from different SEM images were quantify manually, $\mathrm{n}=20$. (D) Western blot analysis of SARS-CoV-2 virions washed from WT- or D614G-infected HNE cultures at $72 \mathrm{~h}$ post infection. Each lane contains a pooled sample from triplicated cultures derived from the same donor. Full-length (FL), S1/S2 cleaved spike protein (S) and nucleocapsid protein (N) were probed. Samples in each pair were loaded based on equal amount of the $N$ protein. (E and $F$ ) $S$ to $N$ ratios $(E)$ and $F L$ to cleaved $S$ ratios $(F)$ were determined by measuring relative intensity of bands in the Western blot image. (G) Summary of $I_{50}$ values of 25 convalescent human sera against WT- and D614G-nLuc viruses. (H) Neutralization curves of three representative human sera. Viral sequence reveals that the serum \#1 was collected from a COVID-19 patient infected with a D614G SARS-CoV2 variant. (I and $J$ ) Summarized $I_{50}$ values $(I)$ and individual neutralization curves $(J)$ of 6 human neutralizing mAbs against both viruses. Data in (C), (E) and (F) are indicated as mean $\pm S D$ and analyzed by unpaired $t$ test; data in $(\mathrm{G})$ and $(\mathrm{I})$ were analyzed by paired $t$ test. N.S., not significantly different. 
A

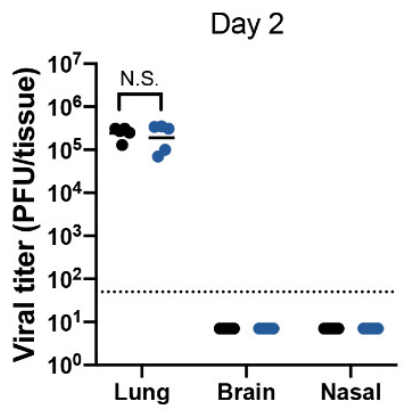

B
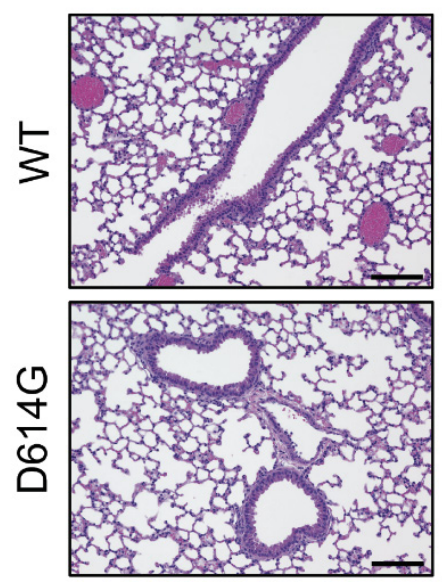

Day 5
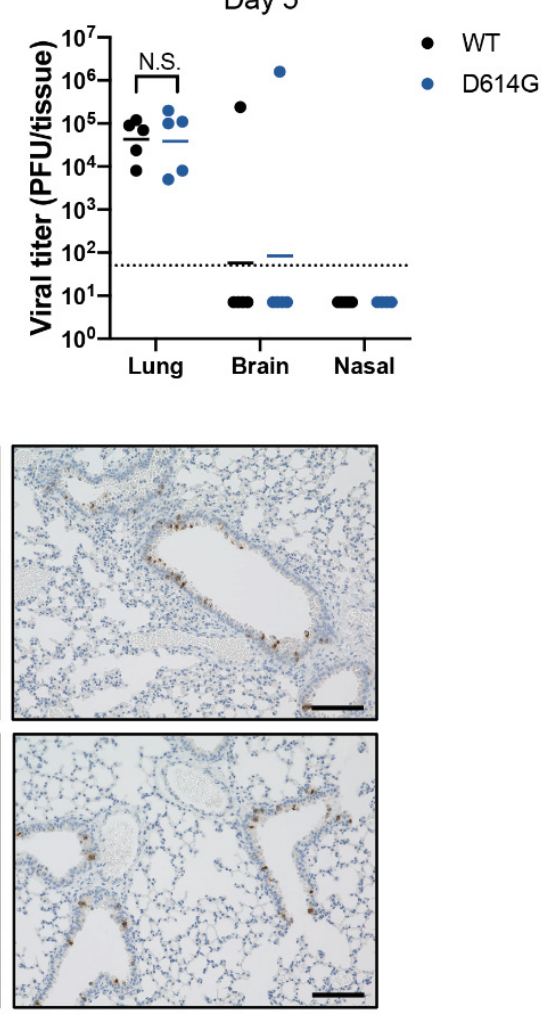

Fig. 3. D614G substitution does not alter SARS-CoV-2 pathogenesis in hACE2 mice. (A) Lung, brain and nasal turbinate titers of WT and D614G infected mice were determined on day 2 and day 5. Each mouse was infected with $10^{5} \mathrm{PFU}$ of the virus ( $n=5$ /group); plaque assay detection limit (1.7 $\log _{10} \mathrm{PFU} / \mathrm{mL}$ ) is indicated as dashed lines. Data are analyzed by unpaired $t$ test. (B) Representative H\&E staining and IHC staining of SARS-CoV-2 N protein in the lung tissues collected from infected hACE2 mice harvested at day 2 post infection, scale bar $=100 \mu \mathrm{m}$. 

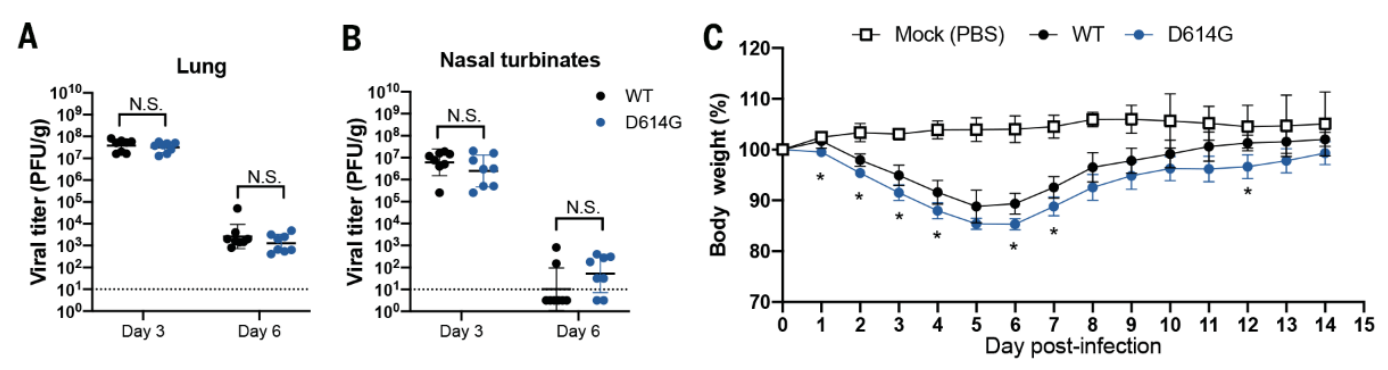

D
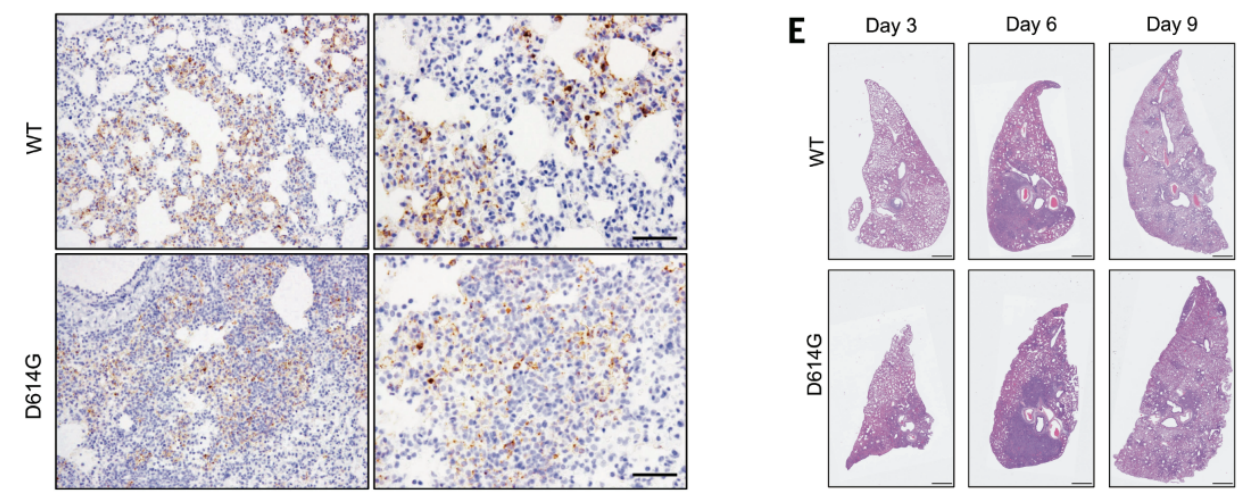

$\mathbf{F}$

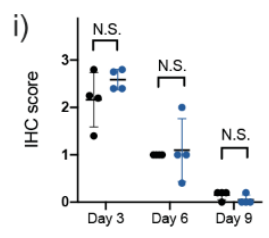

ii)

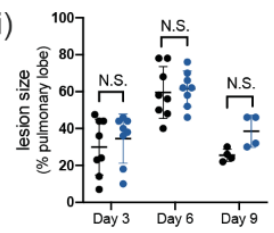

iii)

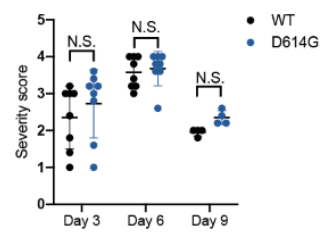

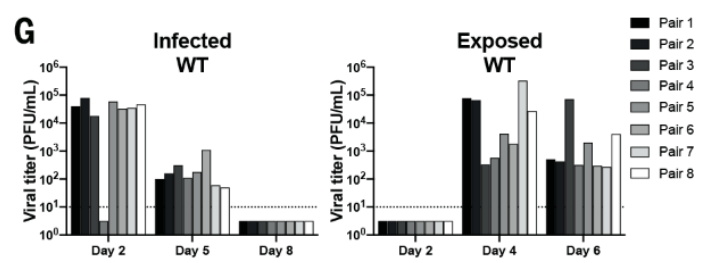

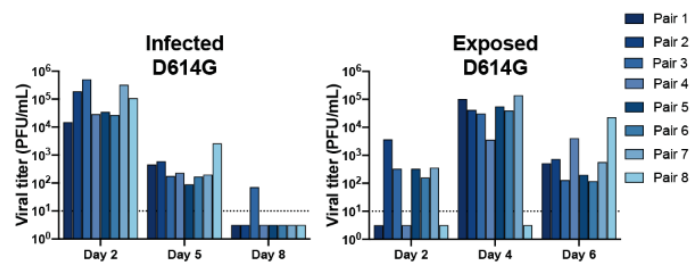

Fig. 4. D614G substitution enhances SARS-CoV-2 transmission in hamsters. (A and $B$ ) Viral titers in the lung $(A)$ and nasal turbinates (B) collected from SARS-CoV-2 infected hamsters at day 3 and 6 . Each hamster was infected with $10^{3}$ PFU of the virus, $n=8 /$ virus for each timepoint; plaque assay detection limit $\left(1 \log _{10} \mathrm{PFU} / \mathrm{mL}\right)$ is indicated as dashed lines. (C). Body weight of mock-, WT- and D614G-infected hamsters ( $n=4$ /group). Hamsters in the body weight study were not subjected to nasal wash sampling. (D) Immunohistochemistry (IHC) staining of SARS-CoV-2 nucleocapsid proteins in representative lung tissues collected from WT- and D614G-infected hamsters at day 3 , scale bar $=100 \mu \mathrm{m}$. (E) H\&E staining of representative lung tissues collected on day 3, 6, and 9 from hamsters infected with WT or D614G, scale bar: 1mm. (F) (i) Quantification of IHC positive cells in hamster lung tissues, following scoring system: 0 , no positive cell; $1,<10 \% ; 2,10-50 \% ; 3,>50 \%$ positive cells in each lobe of lung. (ii) The size of pulmonary lesions was determined based on the mean percentage of affected area in each section of lobes from each animal. (iii) Pathological severity scores in infected hamsters, based on the percentage of inflammation area for each section of the five lobes collected from each animal using the following scoring system: 0 , no pathological change; 1 , affected area ( $\leq 10 \%) ; 2$, affected area $(<50 \%,>10 \%) ; 3$, affected area $(\geq 50 \%)$; an additional point was added when pulmonary edema and/or alveolar hemorrhage was observed. (G) Viral titers in nasal washes collected from infected and exposed hamster pairs in WT and D614G groups; plaque assay detection limit $\left(1 \log _{10} \mathrm{PFU} / \mathrm{mL}\right)$ is indicated as dashed lines. The number of positive hamsters in both exposure groups at day 2 (WT vs. D614G $=0 / 8$ vs. 5/8) are analyzed by Fisher exact test, $p=0.0256$. N.S., not significantly different. 